\title{
Biosynthesis of Copper Oxide Nanoparticles using Extract of E.coli
}

\author{
HAMID REZA GHORBANI*, IMAN FAZELI and ALI ASGHAR FALLAHI
}

Department of Chemical Engineering, Qaemshahr Branch, Islamic Azad University, Qaemshahr, Iran.

${ }^{*}$ Corresponding author: E.mail: Hamidghorbani6@ gmail.com

http://dx.doi.org/10.13005/ojc/310163

(Received: November 25, 2014; Accepted: January 10, 2015)

\begin{abstract}
Copper and copper oxide nanoparticles have attracted much attention of researchers due to their unique optical, electronically, antibacterial properties and low cost of preparation. In this study, we report an environmental benign route for the fabrication of copper oxide nanoparticles using extract of E.coli at room temperature. The obtained nanoparticles were characterized by UV-Vis spectrophotometer, Scanning Electron Microscopy (SEM), and Dynamic Light Scattering (DLS). The synthesized nanoparticles were formed fairly uniform with spherical shape determined by Scanning Electron Microscope (SEM). Dynamic Light Scattering (DLS) was performed to ascertain the size and polydispersity of the nanoparticles.In addition, the results were supported by UV-visspectrophotometer.
\end{abstract}

Key words: Biosynthesis, Copper oxide nanoparticles, Extract of E.coli.

\section{INTRODUCTION}

Nanomaterials are defined as materials with at least one external dimension in the size range from approximately 1-100 nanometers. The synthesis and use of nanoparticles have gained consideration due to their unique electrical, optical, catalytic and magnetic properties which are different from bulk materials ${ }^{1-3}$. Nowadays copper (as metal or copper oxide) is highly regarded due to its specific catalytic, optical, electrical and mechanical characteristics ${ }^{4,5}$. Copper and copper oxide nanoparticles because of their high surfaceto-volume ratio are very reactive and can easily interact with other particles and this property increases their antimicrobial efficiency ${ }^{6}$.Copper oxide nanoparticles are used as gas sensors, catalysis, batteries, high temperature superconductors, solar energy conversion tools and antimicrobial agents ${ }^{7-9}$. There are several methods for the synthesis of copper oxide, including thermal reduction,sonochemical reduction, metal vapor synthesis and chemical reduction. Among all these methods, the biological methods in which, microorganisms and plant extracts are used, have drawn much attention as a simple and viable alternative to chemical procedures and physical methods $^{10,11}$. 
Prasad et al. synthesized copper oxide (Cu2O) nanoparticles by Lactobacillus sp. at room temperature. The dimensions of synthesized copper oxide nanoparticles in this study were between 10 and $20 \mathrm{~nm}^{12}$. Usha et al. used Streptomyces Sp for the synthesis of copper oxide nanoparticles with the size of 100-150 $\mathrm{nm}$. They expressed that the reduction of metal ions may be occurred by reductase enzyme ${ }^{13}$.Singh et al. (2010) using a gram negative bacteria ( $E$. coli) synthesized copper oxide nanoparticles with variable size and shapes under simple experimental conditions, such as aerobic environment, neutral $\mathrm{pH}$ and room temperature. They report that trichloroacetic acid (TCA) precipitated protein fraction of $E$. coli has synthesized copper oxide nanoparticles ${ }^{14}$

In the present work, we have synthesized copper oxide nanoparticles using extract of E.coli. The synthesized nanoparticles were characterizedby UV-Vis spectrophotometer, Scanning Electron Microscopy (SEM), and Dynamic Light Scattering (DLS).

\section{MATERIALSAND METHODS}

The chemical and culture media used in the study supplied fromlslamic Azad University, Tehran, Iran.The Muller-Hinton broth (MHB) was prepared, autoclaved, cooled to about $20-25^{\circ} \mathrm{C}$ and inoculated with a fresh growth of E.coli. The cultured flasks were incubated at $37^{\circ} \mathrm{C}$ for 24 hin an orbital shaker at $100 \mathrm{rpm}$.After incubation, some wet weight of cells (biomass) was collected by centrifugation at $5000 \mathrm{rpm}$ for $15 \mathrm{~min}$ and washed twicewith deionized water,resuspended in $100 \mathrm{~mL}$ of 0.001 $\mathrm{M}$ aqueous CuSO4 solution in $500 \mathrm{~mL}$ Erlenmeyer flask, incubated at $100 \mathrm{rpm}$ for $48 \mathrm{~h}$. The preparedcopper oxide nanoparticleswere collected in a supernatant under sterile condition by centrifugation at $6000 \mathrm{rpm}$ for $20 \mathrm{~min}$ and characterized with different techniques like UV-Vis spectrophotometer, Scanning Electron Microscopy (SEM), and Dynamic Light Scattering (DLS).

\section{RESULTS AND DISCUSSION}

UV-visible spectroscopy is a usefultool to monitor the synthesis of the copper oxide nanoparticles.As shown in the Fig 1, a broad absorption peak was observed at around $365 \mathrm{~nm}$ after 48 hof reaction which is an inference for the synthesis of the copper oxide nanoparticles.UV-vis spectra showed that formed copper oxide nanoparticles were stable in solution at room temperature for more than four weeks.

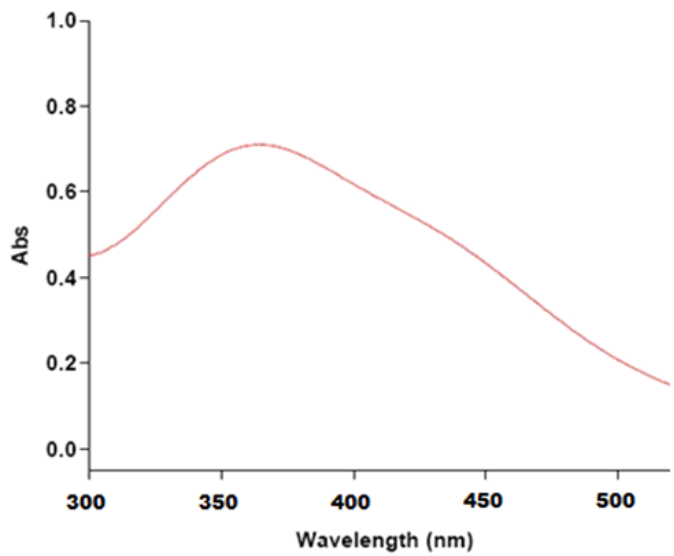

Fig. 1: The UV-VIS absorption spectra of the copper oxide nanoparticles

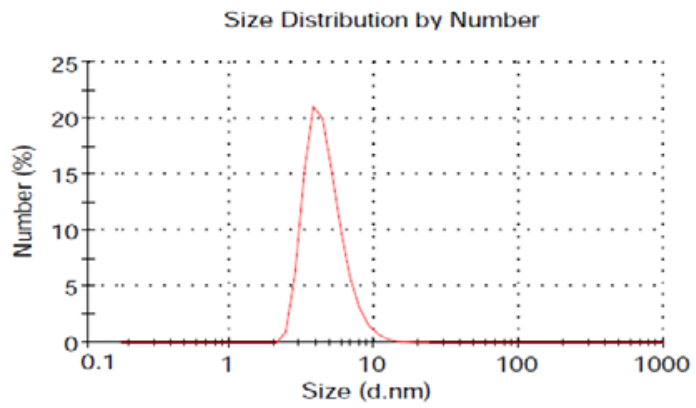

Fig. 2: The particle sizes distribution base on DLS analysis

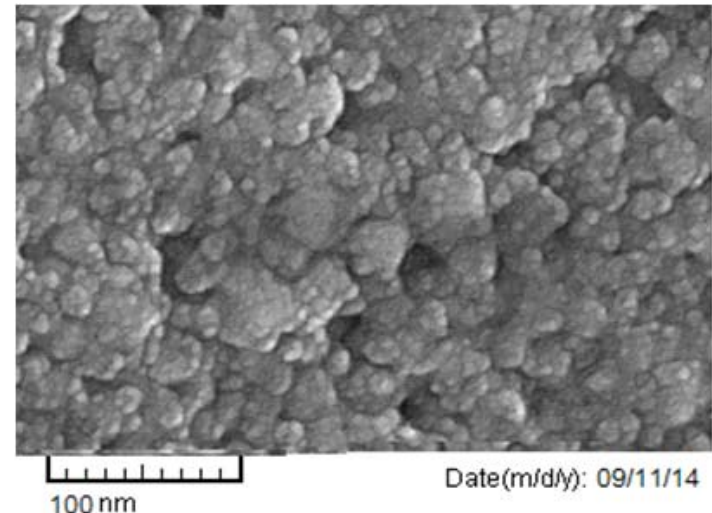

Fig. 3: SEM images of copper oxide nanoparticlesusing extract of E.coli 
Particle size is one of the most important characteristics of nanoparticles.For this reason, dynamic light scattering (DLS) analysis was used. The size distribution of the synthesized nanoparticles was shown in Fig. 2.As is illustrated in figure, mean size of copper oxide nanoparticlesis about $5 \mathrm{~nm}$.SEM analysis of thecopper oxide nanoparticlesindicated the formation of spherical particles(Fig. 3).

\section{CONCLUSIONS}

In this work, facile biosynthesis of copper oxide nanoparticles has been shown using extract of E.coli. This is an environment friendly method to synthesize copper oxide nanoparticles without involving any toxic chemical and stabilizing agent.Themean size of the nanoparticles was estimated about5 $\mathrm{nm}$ by DLS analysis. In addition, nanoparticles were characterized also by UV-Vis spectrophotometer and Scanning Electron Microscopy (SEM).

\section{REFERENCES}

1. Ramesh H Bari, Sharad B Patil, Anil R Bari, International Nano Letters 2013, 3, 12.

2. Issa M El-Nahhal, Shehata M Zourab,Fawzi S Kodeh, Mohamed Selmane, Isabelle Genois,International Nano Letters, 2012, 2, 14.

3. Mostafa Mahinroosta, Journal of Nanostructure in Chemistry, 2013, 3, 47.

4. A. Radhakrishnan; P. Rejani; B. International Journal of Nano Dimension, 2014, 5(6), 519524.

5. M. Ghane; B. Sadeghi; A.R. Jafari ; A.R. Paknejhad, International Journal of Nano Dimension, 2010, 1(1), 33-40.

6. Huang JGunawan,C., Teoh,W.Y., Marquis, C.P. , Amal, R. ACS Nano 2011, 5, 72147225.

7. Liang, J., Tao, Z., Chen, J. Mater Res Bull
2008, 43, 2380-2385.

8. Ren,G., Hu,D., Cheng, E.W.C., Reus,M.A.V., Reip,P. , Allaker, R.P. Int. J.Antimicrob. Agents 2009, 33(6) , 587-590.

9. Zhang,X., Wang,G., Liu,X., Wu,J. , Li,M., Gu,J., Liu,H. , Fang,B. J. Phys. Chem. 2008, 112,16845-16849.

10. Wang, Y.Q., Nikitin,K., McComb, D.W. Chem. Phys. Lett., 2008, 456(4), 202-205.

11. Vitulli,G. , Bernini, M. Chem. Mater., 2002, 14, 1183-1186.

12. Prasad, K., Jha, A.K., Prasad, K., Kulkarni, A.R. Indian J Phys 2010, 84, 1355-1360.

13. Usha, R., Prabu, E., Palaniswamy, M., Venil, C.K., Rajendran, K.R. Glob J Biotechnol Biochem, 2010, 5,153-160.

14. Singh, A.V., Patil, R., Anand, A., Milani, P., Gade, W.N. CurrNanosci, 2010, 6, 365-369. 